\title{
Payment for Environmental Services: Attempts to Consolidate Efforts between Morocco's Environment and Tourism
}

\author{
Oumaima LEHMER \\ Ibn Tofail University, Faculty of Juridical, Economic and Social Sciences, Campus universitaire Maamora BP: 2010 Kénitra, Morocco \\ oumaima.lehmer@gmail.com
}

\begin{abstract}
On the eve of the projects undertaken at the national level, tourism is highlighted with a certain solemnity and considered as a driving machine for the development of economic resources in Morocco. Today, tourism development strategies have set themselves ambitious objectives relating to the development of the sector and the consolidation of its achievements in order to highlight rural and nature tourism. Considering the scope of this issue, Morocco must preconize the improvement of all types of tourism, especially sustainable tourism. From the idea of enhancing and protecting the natural and cultural heritage and promoting tourism and economic activities, we were carried away by other ideas to finally find ourselves faced with a project to define a payment fund for environmental services (PES) dedicated to the preservation, safeguard and enhancement of natural tourist sites such as Tafraout / Ameln, located within the Arganeraie Biosphere Reserve (ABR). This reserve is classified by Unesco as world heritage. It offers exceptional biogeographical and socio-cultural resources, as well as natural potentials, allowing it to become a destination for sustainable tourism and ecotourism. The establishment of a PES system in this region will come to consolidate the efforts made in matter of the environment and nature. However, it can only be done through the determination of the various actors concerned and the definition of the attributions of each of the stakeholders at the level of both regional and local scales. The determination of the environmental service, its cost and its beneficiary, is considered as a panoply of questions that must be answered. At this stage, let us remember that there is indeed a benefit to implant and apply the principle of PES, it's a considerable alternative which is likely to allocate the necessary funding to management costs to the establishment of a preservation system and backup. This modality will make it possible to fill the funding shortfalls of the State for the benefit of the enhancement, structuring and preservation of natural tourist sites. How much will this funding be? For which safeguard approach? Who will be the beneficiary? And so many other enigmas and fogginess will be solved through this article.
\end{abstract}

Keywords: Payments for environmental services, environment, tourism, natural and cultural resources

\section{Introduction}

Tourism is one of the most valuable and most relevant economic sectors. Indeed, the tourism industry has made good results and wealthy incomes for countries endowed with historical, economic, technological and natural potential. These potentialities have facilitated the creation and the diversification of tourism products, as well as the advent of new types of tourism, including environmental tourism, arousing our interest in this publication.

Today, tourism faces several challenges: globalization, customer demands or even high-level competition. This tough competition between tourism actors in order to take pioneering positions, has placed the tourist in a very privileged situation, which has conditioned his behavior, thus modifying his expectations, his requirements, and his motivations.

It is around this postulate that tourist establishments build their policies, strategies, and management approaches around a supreme pillar: Customer satisfaction, which is sometimes achieved to the detriment of the environment and respect for nature.

Although the existence of sustainable and responsible tourism does not date from yesterday, we have noticed a timid awareness towards this phenomenon as well as some problems which are not the least. Sustainable tourism has a heterogeneous character which resides in its environmental dimension that requires a lot of professionalism on the part of the tourist actors.

In the same context, Morocco's decision to open its rural and natural environment to touristic activities is slowed down; from an environmental point of view; for years by the absence of a sustainable management policy. Indeed, the tourist sites of landscape interest are in constant degradation, because of the anarchic exploitation of the tourists, which is in contradiction with the principles of responsible tourism. In the Arganeraie Biosphere Reserve (ABR), in Tafraout/Ameln, more precisely, attempts to reconcile environmental conservation and sustainable tourism development face a multitude of problems due to the multiplicity of actors and their divergent management visions.

It is on the basis of these ideas that we are conducting a research entitled: 'Payments for environmental services as a tool for sustainable tourism development'. These same PES can intervene as an alternative and perspective in the preservation of the environment. Our contribution is a reflection on the creation of a fund (PES) which will ensure the management, sustainability and safeguard of the natural and cultural assets existing in our study area. 


\section{PSE, from general to tourism}

Through our research, we wanted to participate in this debate and try to provide some answers to this multidimensional question: what is the approach and the management mode to benefit from the natural heritage in the Ameln / Tafraout region to ensure a reconciliation between the preservation of existing heritage values and local tourism development? Can we adopt PES as a new tool for tourism development? Can a communication highlighting the advantages of this phenomenon help us attract new tourist targets? What is the capacity of tourists to join a PES program?

This perilous research adventure has piqued our curiosity a number of times. It was obvious to us that there was a highly delicate side that we should face, because nothing is utopian. However, starting to make connections between aspects of our theme was like balm for us.

We think that at this stage, our reader needs to see more clearly the dogma of the innovation that we want to create. Therefore, we believe it is important to dedicate a few lines to PES, to understand the concept and recap its main foundations.

Payment for environmental services is a recent approach, which is particularly implemented within the framework of protected areas having natural, geotourism and eco-tourism potentialities recognized either at the local, regional, national or international scale.

According to Karel. Mayrand and Marc.Paquin (2004) [1] 'The PES is a relatively new mechanism which aims to promote positive environmental externalities through the transfer of financial resources between the beneficiaries of certain ecological services and the service providers or the managers of environmental resources'.

They explain that, 'The fundamental principle of PES is that resource users and communities that are able to generate environmental services must be compensated, and those who benefit from these services must pay them. As a result, these benefits are internalized. From this point of view, the PES approach is similar to the polluter pays principle by creating positive measures to encourage the protection and conservation of the environment'.

PES are also, [2]'a voluntary transaction, where a clearly defined environmental service is purchased by one or more users from one or more suppliers, payment taking place if and only if the supplier actually provides the service'.

This last definition reveals the main characteristics of PES, that it is a voluntary transaction, during which no part of it is obliged to participate. It reconciles nature conservation and economic development by determining the environmental service and its economic value.

Adding to that, the PES mechanism allows the involvement of civil society in ecological policy and promotes the adoption of the green economy, the circular economy and the solidarity economy. Concepts that have many similarities, but also differences with the PES.
We have tried to copy the PES notions on tourism. The principle behind the adoption of this mechanism in the tourism sector refers to the fact that each natural ecosystem has several marketed services, including the cultural service relating to the recreational component of nature discovery, which includes tourist value. Thus, thanks to the PSE tool, it will be possible to assess the economic value that tourism actors can grant in order to discover the ecosystem while contributing to its preservation.

Out of all the markets of environmental services, the markets for landscape conservation services are the least developed. These services are in demand nationally and internationally. The ecotourism industry is perhaps one of the main beneficiaries - and therefore demanders - of landscape preservation services. At present, governments are the main providers of services related to scenic beauty, through the creation of protected areas or the protection of natural or cultural heritage sites. However, we are seeing an increase in the provision of landscape beauty preservation services by local communities and indigenous people as this concept may also include cultural practices, traditional land uses or architectural features. Landell-Mills and Porras[3] studied 51 payment systems for landscape preservation services. They found that this market had not reached maturity and had serious shortcomings; among other things, the ecotourism industry may be willing to pay for the provision of these services and there are no sophisticated payment mechanisms.

The idea of natural heritage offers another interesting opportunity regarding the establishment of PES. Like what exists for cultural heritage, it may be desirable to recognize a collective interest in the preservation of nature. PES systems represent a more efficient, flexible and economical solution than the creation of traditional protected areas. These systems can be putted in place when the creation of protected areas is not possible for socio-economic or political reasons. They are simpler to manage and provide a more flexible range of land uses and extractive activities that promote both economic development and environmental protection. These PES frameworks take the form of a compensation system, which contributes to the development of sustainable tourism, a sector that constitutes a particular interest to us.

\section{Methodological Approach}

As we mentioned previously, our research aims to identify an empirical model for the implementation of PES and to reproduce it on the tourism sector, in particular sustainable tourism, for its dimension concerned with the environment and ecology.

Going from the 'polluter pays' principle, and after the recast of the natural and cultural capital of the studied area. We followed methodological steps which represent a set of actions to have concrete, realistic and logical results:

Literature review of aspects and concepts related to our study;

- Documentary research and collection of data related to environment and tourism at national and regional level; 
- Comparative studies with countries having the same cultural, touristic and economic context;

- Prospecting through field studies;

- Self-administered questionnaires and survey destinated to the local population (200) and tourists (400);

- Developing questionnaires in English, French, Arabic and Amazigh (local language);

- Realization of a territorial diagnosis;

- Contact of different public actorsin the tourism domain;

- Interviews with project stakeholders;

- Analysis of statistics and data collecting using SPSS and Sphynx for quantitative data;

- Financial forecasts and business plan;

- Digital Marketing study;

- Elaboration of an adapted PSE model to our context.

Every axis of this methodological approach had been transformed into information, data and results, which allowed the concrete birth of the idea of the PES conception.

\section{PES in the Biosphere}

Before spreading the results of the studies and surveys, we think we should take a closer look to the studied area, On December 8, 1998, the Arganeraie was declared by UNESCO as the first Biosphere Reserve in Morocco covering an area of approximately 2.5 million hectares.

Ameln / Tafraout, as a part of it, is a region that presents a whole myriad of characteristics that qualifies it among the special touristic spots. Whether it is the fauna, flora, history or population, all these assets polish the brand image of this place. The territory holds a well-diversified fauna and flora wealth. The Argan tree, being the main element of this wealth, represents a strong symbolic connotation among the inhabitants. Indeed, it is the economic lung of the RBA, especially as its uses are multiple. Rough cliffs, pink granite mountains, perched 1000 meters above sea level, nestled around almond orchards, olive trees, and aromatic and medicinal plants surround it.Rare and endangered species find their natural haven in the surroundings of the Amelne fields. It is also endowed with a rich artisanshipand local products in abundance processed by local cooperatives to perpetuate the unique heritage of the region.

Tafraout / Ameln is also known for its rock art and its prehistoric sites, which enhance and contribute to the notoriety of the archaeological heritage, which attract not only tourists but also researchers, scholars and promoters of prospecting programs.

This unique and particularly precious heritage has both touristic and scientific interest and provides a panel of information on ways of life, tools, clothing, ceremonies and everything that made up the material and spiritual world of vanished civilizations.

The local population, is strongly attached to spiritualties, the town is precisely known by a very large number of 'Marabouts'.

In addition, the cuisine of the region is also considered asa very attractive cultural element, regarding its richness and variety. It has been able to retain its originality and specificity despite the globalization effects.

Indeed, the global diagnosis allowed us to establish an inventory of our territory (Tafraout / Ameln), and to confirm, not only, the presence of strong natural and cultural potentialities mentioned previously, but also the existence of some weaknesses which we are trying to remedy through our theory. This same diagnosis also made it possible to reveal that this natural site can implement the PSE project.

As a reminder, the research that we carry out is based on an approach, which consists on highlighting the close link between tourism and environment. While placing ourselves in a defined context: the tourist, between his real needs and potentials and his psychological load. On the other hand, the environment and the impact of the tourist's usual practices on it. The study also includes the specificities of the local population, its position on this subject, its needs and its participation.

In order to move away from theory and get closer to practice, our first survey was carried out through a questionnaire intended to tourists from the Ameln / Tafraout valley, it took place over a period of one year, and gave rise to more than 400 interviews.

To be able to manage the natural resources of our study area, we have defined an environmental service: a conservation program. Legally speaking, after having a deep analysis of the juridical texts on this subject, it turns out that nothing prevents us from putting it into effect. Especially since it is not taking the form of a tax but a contribution. The appellation 'tourist tax' was only used to make the concept understood among visitors.

The first challenge in developing a PES system is to define measure and quantify the environmental services sought. This requires scientific knowledge and stakeholder consultation to determine which services will attract beneficiary participation. The most important thing is to identify the services required and the beneficiaries interested by the project, then to determine the levels of services desired.

The primary objective of this survey was to determine the Consent to contribute (CTC) of tourists, of course after giving them a view relative to settings of the program, which will provide the development and the structuring of sustainable tourism products, (geotourism, ecotourism, cultural tourism), as well as, the determination of the capacity to pay for natural tourist sites via a 'tourist tax'.

We have chosen the region visitors as the main participants in this PSE transaction, for two main reasons. The first one, is the natural and cultural resources of the region that will carry the project, which we have previously enumerated. The second is a bunch of echoes that seem to underline that; the tourists coming to discover Ameln are concerned by the environment. The survey carried out demonstrated that these tourists are ready to contribute with an average sum of $\mathbf{5 €}$ in return for guaranteeing the implementation of the conservation program. 
The establishment of a PES system requires the creation of a funding mechanism that will collect and manage the money contributed by beneficiaries. In theory, the price paid by beneficiaries should not exceed the value of the services provided. Therefore, estimating the value of environmental services is one of the biggest challenges in setting up PES systems. This assessment process requires economic analysis and extensive consultations with beneficiaries in order to determine contributions that are, on the one hand, acceptable to them and, on the other hand, high enough to fund the PES system and the provision of the desired environmental services.

The program offered in return for this payment is a set of actions that promotes tourism and protect the environment. We produced it based on our formal and less formal interviews and discussions with visitors, locals, decisionmakers, scientific experts and tourism stakeholders. It is a range of actions that brings together the needs of clients who are becoming more and more demanding. It includes various approaches, which revolve essentially around the conservation of the natural and cultural heritage, the development of tourism, the development of the tourist offer, the improvement of access to tourist information and the quality of services.

Actions to which we have tried to give a cost in our financial part of the study, which informed us about the figures, related to the project and its socio-environmental impact. In this direction, and in order to study the profitability of our investment, we have established a cash flow forecast with the objective of measuring our return on certain expenses incurred within the framework of the conservation program. After combining the statistical study on the commitment of tourists to pay for ES, the study of facilities and forecasts of current and future visits. Our study shows a positive cash flow from the first year of operation.

Let's take as an example the operation related to fauna and flora.

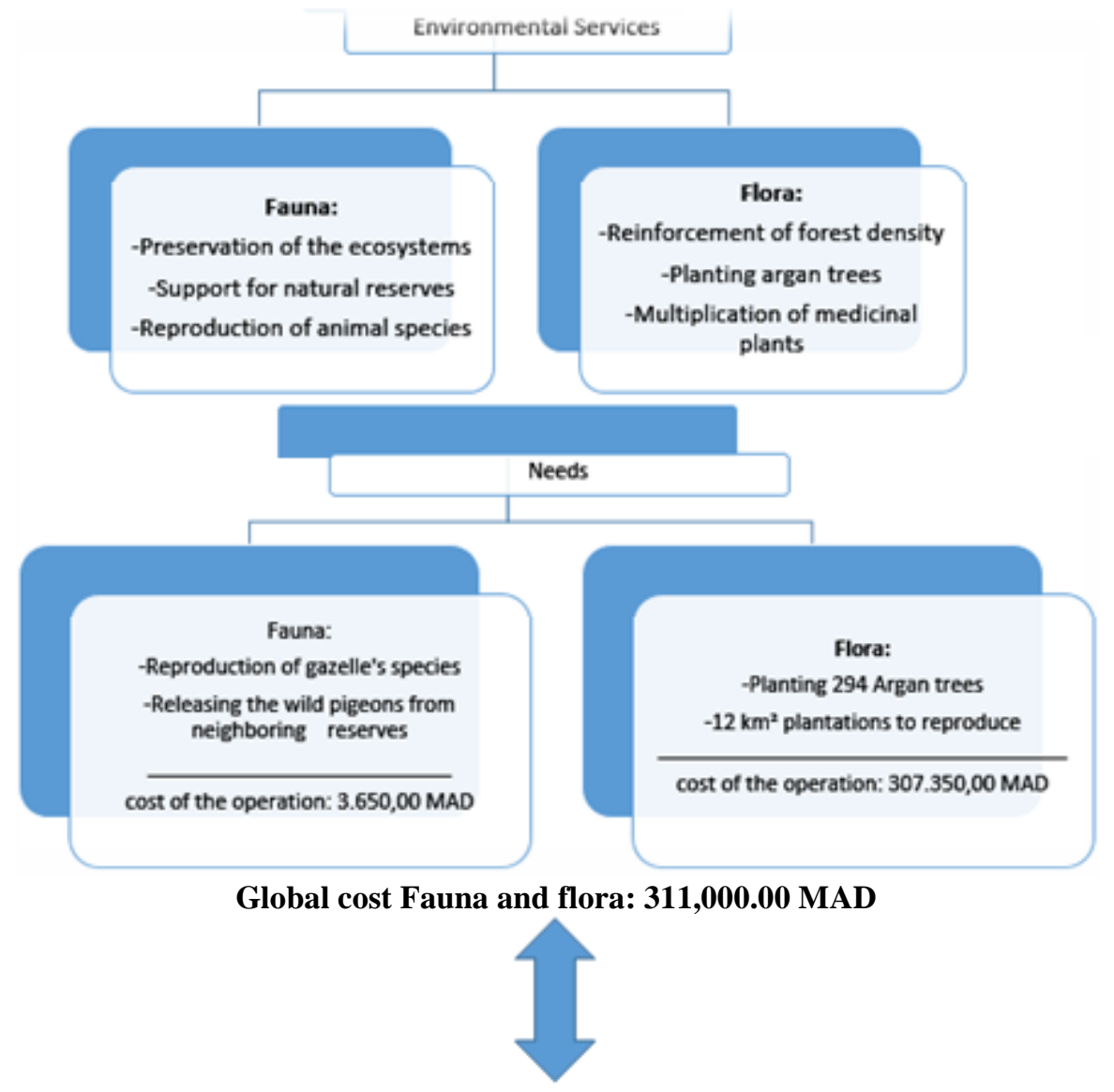

Conversion into tourist units: 6220 Tourists convertible to PSE

[4] Figure 1: Representative diagram of the fauna-flora operation

We should underline that each March of every year, witnesses the visit of more than 3000 tourists. March 2020 witnessed more than 4,500 cancellations due to the COVID19 virus.

In addition, we believe that our PSE project will generate employment throughout the year, not only in March. Because we intend to market it to prospects through a good digital Marketing strategy, and to the local population through communication and environmental education.

We have highlighted here the specificity of PES relating to job creation, for the social dimension of the PES concept. Indeed, it is distorted if it does not bring any interest to the natives. In our case, we will focus primarily on its financial 
contribution, because that's what the population needs the most at the moment.

All the more so, to guarantee its sustainability, the touristic activity must contribute to the empowerment of the local population through her participation in decision-making and also in the development process. To do so, we aimed the inhabitants in the last part of our investigation. We asked them several questions related to their vision of PES, after outlining their advantages, disadvantages and limitations. Let us remember that during our interviews with the inhabitants - illiterate or not - they gave us their appreciations and points of view about the project in general, which was positive. Some of them were even charmed and started to project themselves into their new tourist cocoon.

However, the majority of those questioned inhabitants suggested that the manager and the guarantor of this project should be an association. In fact, this suggestion does not contradict our proposition that we kept to ourselves during the interviews so as not to influence the population's opinion. Indeed, if a local decision-maker of the type Municipality, Rural Tourism Developers or Tourism Delegation manage the income of the project, we will fall into legal anomalies. Because PES are not a compulsory tax. In addition, we have noticed that the local population trusts a particular association, it is a touristic association which has already made many efforts in the region.

However, this association must be guided, directed and advised by a more formal entity which has more experience. Because, claiming to put an idea into practice without going through the point of view of its actors, is to try to solve an equation with several parameters without using variables. To do so, we have contacted local decision-makers in the region, who will be the conciliators who are going to ensure the success of the PES system. The tourism delegation, the Regional Council of Tourism, the Touristic and Rural Development Network, the Souss Massa regional council and the High Commission for Water and Forests and the Fight Against Desertation could be intermediaries who will intervene in connecting buyers and sellers and in the management of activities related to the implementation of PES. Especially that after meeting with them we were able to deduce that the efforts they made in environment and tourism are considered parallel to our vision of the project which aims at the respect, the preservation and the development of the heritage resources, natural, cultural and social areas for tourists.

\section{Conclusion}

Our project to set up a PES model for the implementation of the preservation and conservation program in the Biosphere reserve of the argan grove was considered chimerical at the start of this study.

However, the interest shown in this concept by the tourist population, the natives and the local decision-makers motivated us to tie up this concept, to dissect it and to remodel it so that it is adapted to Tafraout / Ameln in a particular way and to the tourism sector in general.
Indeed, our E-marketing study related to our research theme has allowed us to detect that we are likely to attract a good number of visitors who are increasingly showing a particular interest to natural attributes and a certain environmental sensitivity.

On the other hand, our environmental communication has shown that the local population has a predisposition to get involved in the protection of the environment.

This supports our idea of encouraging tourists and inhabitants to contribute and protect the natural and cultural heritage resources. And therefore to adopt our PSE project.

The formulation of this project's plan faced a multitude of constraints, starting with the identification of the services potentially sought by the beneficiaries, which requires indepth knowledge of the system; diversifying these services; $t$ attributing a monetary value to it; selecting mechanisms that maximizing the net benefit...

Working on this project has been a difficult and controversial task, but it was not impossible to solve. Today we are reaping the fruit of our idea, in fact, the municipality of Ameln / Tafraout intends to formalize the start of our PES project in the region, during the following months.

\section{References}

[1] K. Mayrand, M.Paquin, 'Payment for environmental services',Study and evaluation of current systems,pp.30-40,2004.

[2] B.Dominique, 'Economic References For Sustainable Development', Economic Council For Sustainable Development, n 17,2010.

[3] Landell-Mills, N.and Porras, 'A Global review of markets for forest environmental services and their impacts on the poor', 2002.

[4] O.Lehmer, 'Payments for environmental services as a tool for sustainable tourism development'.

\section{Author Profile}

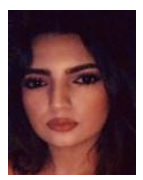

Oumaima LEHMER completed her Master of Marketing and Sales in 2016 from Institute of Business Administration, Metz France. Presently she is a PHD student in Ibn Tofail University Morocco. Her research interests are Marketing, Management, Tourism and Environment. 